\title{
Association of Silent Myocardial Ischemia in Obese Patients with Metabolic Syndrome
}

\author{
ELHAM M. YOUSIEF, M.D.*; AHMED A. KANDEEL, M.D.**; MAHMOUD SHAABAN, M.Sc.*** and \\ YASSER ALSAYED, M.D.** \\ The Departments of Internal Medicine Unit, Kasr Al-Ainy Hospital*, Nuclear Medicine Unit, Kasr Al-Ainy Hospital (NEMROCK)**, \\ Cairo University and Nuclear Medicine Unit, Beni Suif University***
}

\begin{abstract}
Background: Egypt is among the first four countries suffering from obesity worldwide. The function of waist circumference [WC] as an independent indicator of silent myocardial ischemia [SMI] remains unknown in Egyptian obese patients. Thus, we aimed to detect SMI in a cohort of Egyptian obese individuals with metabolic syndrome [MS] and to examine its associations with various clinical and diagnostic results.
\end{abstract}

Methods: Fifty obese patients (G1) without overt coronary artery disease [" 60 percent" females and " 40 percent" males; mean age $40.2 \pm 4.5$ years] and 50 ages \& sex matched nonobese subjects who served as control group (G2) were enrolled in this study. Anthropometric tests were taken for both subjects. Laboratory evaluation included fasting blood sugar, serum triglycerides, high density lipoprotein cholesterol. Assay of serum uric acid, urea, creatinine and microalbuminuria. MS was established through the revised National Education Program on Cholesterol [NCEP-R]. Tc99 m SestaMIBI SPECT gated myocardial perfusion imaging [GSPECT] was used for SMI screening. Pearson Moment correlation equation was used to check correlation between different variables. The logistic regression analysis was performed univariate and multivariate and the linkages between SMI and significant variables were established.

Results: In (G1), 13/50 [26\%] had SMI as compared to $2 / 50$ [4\%] among (G2) $p=0.0001]$. GSPECT positivity significantly correlated with HDL $(r=0.4 ; p=0.02)$; microalbuminuria $[r==0.5 ; p=0.04]$; and WC $[r=0.6 ; p 0.04]$. Neither WC (OR 1.042; CI 0.8701.248; $p=0.654$ ) nor microalbuminuria (OR 1.794 , CI $0.6734 .784 ; p=0.243$ ) were considered as independent predictor of SMI.

Conclusion: A significant association of SMI has been found among a cohort of Egyptian obese patients with MS using Tc99 $\mathrm{m}$ SestaMIBI GSPECT. Considering the fact, we believe that the latter has a place as a screening tool; whenever the diagnosis is made the better the result.

Key Words: Obesity - Ischemia - Metabolic syndrome - Silent myocardial ischemia.

Correspondence to: Dr. Elham M. Yousief, The Department of Internal Medicine Unit, Kasr Al-Ainy Hospital, Cairo University

\section{Introduction}

IN the absence of angina or anginal equivalents, silent coronary artery disease $[\mathrm{CAD}]$ is characterized as the occurrence of myocardial ischemia or an infarction [1]. While silent CAD is the most frequent manifestation [2]. There are no screening guidelines for determining its burden in patients with traditional coronary atherosclerosis risk factors [3].

Over the years the prevalence of metabolic syndrome [MS] [4] and abdominal obesity has gradually increased [5] . Different organizations, such as the National Cholesterol Education Program (NCEP) $[6,7]$ the International Diabetes Federation (IDF)[8] and the World Health Organization (WHO) [9] have published various criteria for defining metabolic syndromes. It was proposed that individual components be of MS were proposed to interact synergistically to cause or accelerate atherosclerosis [10].

However, several questions have been raised recently regarding the impact of MS on CAD or SMI risk compared with its components [11].

Recently it was reported that high waist circumference (WC) and therefore abdominal obesity was a higher risk factor for cardiovascular disease (CVD) than general obesity $[12,15]$ with a clear correlation with MS $[\mathbf{1 3 , 1 4 , 1 6 ]}$. Lakka et al., showed an increase in all cause mortality in men with metabolic syndrome using a given high WC of $>102 \mathrm{~cm}$ instead of $\geq 94 \mathrm{~cm}$ [17].

However, there is still a large population segment with WC average of $\geq 94 \mathrm{~cm}$ that remains at an increased risk of CVD [16,18-20]. In this way 
we aimed to detect silent myocardial ischemia [SMI] in a cohort of obese Egyptians and to analyze its correlations with different clinical and diagnostic data.

\section{Patients and Methods}

\section{Study population:}

The research has been accepted by the scientific review board of Cairo University's local ethics committee. It was a cross-sectional analysis performed on 50 obese Egyptian patients [30 females and 20 males] without documented CAD. Patients with positive family history, diabetes [fasting blood sugar $(\mathrm{FBS})>126 \mathrm{mg} / \mathrm{dl}$ ], hypertension [defined as blood pressure $>140 / 90 \mathrm{mmHg}$ and/or antihypertensive drug use], elevated serum creatinine [>1.2mg/dl], abnormal renal sonography, urinary tract infection and other cardiovascular diseases have been excluded. Fifty Age and non-obese subjects matched by sex served as a control group.

All patients and controls were subject to full history and clinical examination including blood pressure measurement (BP), weight, height, WC, waist hip ratio (WHR), waist-height ratio (WHtR), and single photon emission gated myocardial perfusion [GSPECT] computed tomography using Tc99 m Sestamibi. WHR was considered to be increased if there were $>0.9$ in men and $>0.85$ in women [21] and the cut-off point for WHtR was 0.5 for both genders [22]. After overnight fasting, biochemical analyzes were performed including FBS, high density lipoprotein cholesterol (HDL), triglycerides (TG), urea, creatinine, and uric acid. Microalbuminuria assay was conducted using competitive immunoassay enzymes, using IMMULITE2000 tools and albumin kits [23]. Microalbuminuria is characterized as a concentration of $20-200 \mathrm{mg} / 1$ of urinary albumin, whereas macroalbuminuria is considered to be the concentration of urinary albu$\min >200 \mathrm{mg} / 1$ [24]. Metabolic syndrome has been diagnosed with three or more of the following risk factors: $\mathrm{WC}>88 \mathrm{~cm}$ in women and $>102 \mathrm{~cm}$ in men, TGs $>150 \mathrm{mg} / \mathrm{dl}$ in adults, HDL $<40 \mathrm{mg} / \mathrm{dl}$ in male and $\langle 50 \mathrm{mg} / \mathrm{dl}$ in women, $\mathrm{BP}>130 />85 \mathrm{mmHg}$, FBS $>110 \mathrm{mg} / \mathrm{dl}$ based on the requirements of the National Plan for Cholesterol Education-Adult Care Panel III (NCEP-ATP III) [6,7,13] .

Myocardial gated single photon emission computed tomography:

Dipyridamole was intravenously administered over 4-6min to cause pharmacological stress $(0.56 \mathrm{mg} / \mathrm{kg}$ body mass $)$. A small rise in heart rate and a slight decrease in blood pressure support the drug's pharmacological impact, with images taken $15 \mathrm{~min}$ after infusion with dipyridamole. Tc-99 m Sesta-MIBI was injected with continuous ECG and blood pressure monitoring at a dosage of 22-25 $\mathrm{mCi}(814-925 \mathrm{mBq})$. Imaging was carried out over 2 days (within a period of 1 week) during the stress and rest phases using a dual head gamma camera (Philips Axis, Philips, The Netherlands) under the following conditions: Patient with elevated left arm (180o arc), counterclockwise rotation, $128 \times 128$ matrix, and 64 image/arc views $\left(180^{\circ}, 45^{\circ}\right.$, anterior right oblique and $135^{\circ}$ left oblique). A ramp filter and convection filter with oblique angle reformatting (short axis and long horizontal and vertical axis) (Butterworth filter; Texas Instruments, Texas, USA); For GSPECT, the processing of ECGsynchronized data was carried out using an R-wave trigger (8 frames/cardiac-cycle). Imaging was done 3060min after administration of SestaMIBI during the rest process. The GSPECT was analyzed in a joint session by three board-certified nuclear medicine physicians (two with 10 years of experience, and the other with 20 years' experience). Myocardial perfusion of the left ventricular (LV) walls was visually assessed for defects [myocardial perfusion defects (MPDs)]. The 17 myocardial segments were assigned to the territories of the left anterior descending artery [LAD], right coronary artery $[\mathrm{RCA}]$, and the left circumflex coronary artery [LCX] [25]. We classified patients as GSPECT negatives and GSPECT positives.

\section{Statistical method:}

All statistical calculations were done using computer program SPSS (Statistical Package for the Social Science; SPSS Inc., Chicago, IL, USA) release 15 for Microsoft Windows. Student $t$-test was used to analyze differences in numerical data and chi-squared test was used to determine the differences between proportions of categorical data. Correlation between different variables was tested using Pearson Moment correlation equation. Numerical data were tested for normality using Kolmogorov Smirnov test. Univariate logistic regression was performed to identify the associations between SMI and significant variables. Multivariate logistic regression analyses were performed using a stepwise forward selection approach. $p$-values $<0.05$ were considered statistically significant.

\section{Results}

General characteristics of the study group [n. 50]:

This study included 50 obese patients [Group 1 (G1) 30 females " $60 \%$ " and 20 males " $40 \%$ "] 
and 50 non-obese subjects as a control group (G2). G1 patients fulfilled the criteria for MS versus none in G2. Their different clinical and physical parameters are shown in Table (1) where significant statistical differences were elicited among all the parameters except for age and blood pressure measurements.

Table (1): Clinical and physical parameters in obese patients and controls.

\begin{tabular}{llll}
\hline & $\begin{array}{c}\text { Obese } \\
\text { patients (G1) }\end{array}$ & $\begin{array}{c}\text { Non-obese } \\
\text { control (G2) }\end{array}$ & $\begin{array}{c}p \text { - } \\
\text { value }\end{array}$ \\
\hline Age (ys) & $40.2 \pm 4.5$ & $41.2 \pm 4.1$ & 0.6 \\
Sex distribution: & & & - \\
$\quad$ Females & $30(60 \%)$ & $30(60 \%)$ & \\
$\quad$ Males & $20(40 \%)$ & $20(40 \%)$ & \\
WC (cm) & $116.9 \pm 15$ & $77 \pm 5.2$ & 0.0001 \\
WHR & $1 \pm 0.1$ & $0.7 \pm 0.1$ & 0.0001 \\
WHtR & $0.7 \pm 0.1$ & $0.5 \pm 0.02$ & 0.0001 \\
BMI & $37.28 \pm 5.9$ & $23.5 \pm 1.3$ & 0.0001 \\
SBP (mm Hg) & $115.9 \pm 13.1$ & $112.4 \pm 10.3$ & 0.8 \\
DBP (mm Hg) & $74.4 \pm 11$ & $71.8 \pm 9.3$ & 0.9 \\
\hline
\end{tabular}

G1: Group 1. G2: Group 2. BMI: Body mass index.

WC : Waist circumference. $\quad$ SBP: Systolic blood pressure.

WHR : Waist hip ratio. $\quad$ DBP:Diastolic blood pressure.

WHtR : Waist-height ratio.

Values are expressed as mean \pm SD or no (\%).

The laboratory data are detailed in Table (2). FBS, uric acid, TG and microalbuminuria were significantly higher in G1 while HDL was significantly lower in G1 with no difference in serum urea and creatinine.

Table (2): Laboratory data of obese patients and controls.

\begin{tabular}{|c|c|c|c|}
\hline & $\begin{array}{c}\text { Obese } \\
\text { patients }(\mathrm{G} 1)\end{array}$ & $\begin{array}{l}\text { Non-obese } \\
\text { control (G2) }\end{array}$ & $\begin{array}{c}p- \\
\text { value }\end{array}$ \\
\hline FBS (mg \%) & $102 \pm 12.7$ & $93.7 \pm 12$ & 0.004 \\
\hline Creatinine (mg/dl) & $0.6 \pm 0.1$ & $0.6 \pm 0.1$ & 0.9 \\
\hline Urea (mg/dl) & $11.4 \pm 3.6$ & $12.5 \pm 4$ & 0.9 \\
\hline Uric acid (mg/dl) & $4.3 \pm 0.9$ & $3.5 \pm 0.8$ & 0.01 \\
\hline TG (mg/dl) & $439.4 \pm 190.5$ & $150 \pm 31$ & 0.000 \\
\hline HDL (mg/dl) & $33.3 \pm 7.7$ & $48 \pm 0.8$ & 0.000 \\
\hline $\begin{array}{l}\text { Microalbuminuria } \\
(\mathrm{mg} / \mathrm{l})\end{array}$ & $37.2 \pm 4$ & $17 \pm 5$ & 0.008 \\
\hline MS (No. \%) & $50 / 50(100 \%)$ & 0 & 0.000 \\
\hline
\end{tabular}

\section{Myocardial perfusion GSPECT:}

Of the 50 obese patients who were exposed to cardiac pharmacological stress monitoring [Dipyridamole] with subsequent GSPECT; 37 cases [74\%] were negative and 13 cases [26\%] were positive for SMI, 6/20 [30\%] males and 7/30 females [23.3\%]. Most lesions were of moderate grade [81.2 percent].

The vascular area most frequently affected was RCA with LCX and LAD similarly affected. Ischemia was found in a single vascular territory except in 3/13 [23\%] where male cases resulted in the involvement of two vascular territories. Two patients in G2 demonstrated positive GSPECT $[2 / 50 ; 4 \%$ vs. $26 \%$ in $\mathrm{G} 1 ; p 0.001]$.

\section{Associations and Cox-regression analysis:}

- The Pearson correlation test revealed substantial statistical correlations between SMI and MS ( $r$ $0.7, p 0.02)$, WC $(r 0.6, p 0.04), \mathrm{WHtR}(r 0.6, p$ $0.03)$, HDL $(r-0.5, p 0.02)$, and microalbuminuria $(r 0.5, p 0.04)$. All other variables tested (age, sex, FBS, TG, and WHR, and BMI) showed no significant association $(p>0.05)$ (Table 3$)$.

Table (3): Associations of SMI and patients' data in obese patients (G1).

\begin{tabular}{|c|c|c|}
\hline & Variable & G1 [n. 50] \\
\hline & Age & $\begin{array}{l}r=0.3 \\
p 0.5\end{array}$ \\
\hline & Sex & $\begin{array}{l}r=0.2 \\
p 0.6\end{array}$ \\
\hline & FBS & $\begin{array}{l}r=0.2 \\
p 0.5\end{array}$ \\
\hline & TG & $\begin{array}{l}r=0.3 \\
p 0.09\end{array}$ \\
\hline & HDL & $\begin{array}{l}r=-0.5 \\
p 0.02\end{array}$ \\
\hline & Microalbuminuria & $\begin{array}{l}r=0.5 \\
p 0.04\end{array}$ \\
\hline & WC & $\begin{array}{l}r=0.6 \\
p 0.04\end{array}$ \\
\hline & WHR & $\begin{array}{l}r=0.2 \\
p 0.9\end{array}$ \\
\hline & WHtR & $\begin{array}{l}r=06 \\
p 0.03\end{array}$ \\
\hline & BMI & $\begin{array}{l}r=0.2 \\
p 0.2\end{array}$ \\
\hline & MS & $\begin{array}{l}r=0.7 \\
p 0.02\end{array}$ \\
\hline $\begin{array}{l}\text { SMI } \\
\text { G1 } \\
\text { WC } \\
\text { WHR } \\
\text { WHtR }\end{array}$ & $\begin{array}{l}\text { : Silent myocardial ischemia. } \\
: \text { Group 1. } \\
\text { : Waist circumference. } \\
\text { : Waist hip ratio; } \\
\text { : Waist-height ratio. }\end{array}$ & $\begin{array}{l}\text { BMI : Body mass index. } \\
\text { FBS : Fasting blood sugar. } \\
\text { TG : Triglycerides. } \\
\text { HDL : High density lipoprotein. } \\
p \text {-Value }<0.05 \text { is significant. }\end{array}$ \\
\hline
\end{tabular}


- Analysis of univariate regression revealed that MS (OR 1.011; CI 0.971-1.156; $p=0.02$ ), WC (OR 2.006; CI 0.913-2.950; $p=0.01$ ), WHtR (OR 1.012; CI 1.427-2.078; $p=0.02$ ), HDL (OR 2.009; CI 0.903-2.050; $p=0.01$ ) and micro-albuminuria (OR 1.011; CI 0.931-1.186; $p=0.02$ ) were significant SMI predictors (Table 4).

- All relevant variables from the univariate analysis have been included in a stepwise multivariate regression. Accordingly, checking for the beneficial effect of micro-albuminuria and $\mathrm{WC}$ on the existence of silent MI was selected.

The analysis however showed that neither WC (OR 1.042; CI 0.8701.248; $p=0.654$ ) nor microalbuminuria (OR 1.794, CI 0.673-4.784; $p=0.243$ ) were considered to be independent predictors of SMI (Table 5).

Table (4): Significant predictors of silent myocardial ischemia in obese patients (G1) by Univariate regression analysis [n. 50].

\begin{tabular}{lccc}
\hline Variate & $\begin{array}{c}\text { Odds } \\
\text { ratio }\end{array}$ & $\begin{array}{c}95 \% \text { Confidence } \\
\text { interval }\end{array}$ & $\begin{array}{c}p- \\
\text { value }\end{array}$ \\
\hline WC & 2.006 & $0.913-2.950$ & 0.01 \\
WHtR & 1.012 & $1.427-2.078$ & 0.02 \\
HDL & 2.009 & $0.903-2.050$ & 0.01 \\
MS & 1.001 & $0.971-1.156$ & 0.02 \\
Microalbuminuria & 1.011 & $0.931-1.186$ & 0.02 \\
\hline$p$-Value $<0.05$ is significant. & \multicolumn{2}{l}{ WHtR : Waist-height ratio. } \\
G1: Group 1. & HDL & : High density lipoprotein. \\
WC: Waist circumference. & MS & : Metabolic syndrome.
\end{tabular}

Table (5): Significant predictors of silent myocardial ischemia in obese patients (G1) by Multivariate regression analysis [n. 50].

\begin{tabular}{lccc}
\hline Variate & $\begin{array}{c}\text { Odds } \\
\text { ratio }\end{array}$ & $\begin{array}{c}95 \% \text { Confidence } \\
\text { interval }\end{array}$ & $\begin{array}{c}p \text { - } \\
\text { value }\end{array}$ \\
\hline WC & 1.042 & $0.870-1.248$ & 0.654 \\
Microalbuminuria & 1.794 & $0.673-4.784$ & 0.243 \\
\hline
\end{tabular}

$p$-Value $<0.05$ is significant

G1 : Group 1.

WC: Waist circumference.

\section{Discussion}

Metabolic syndrome (MetS) is a cluster of risk factors linked to insulin resistance, subclinical inflammation, increased future risk of diabetes and coronary artery disease (CAD) [10]. Because of its high percentage of body fat, abdominal obesity and insulin resistance, South Asians are more likely to develop MetS [26]. Despite some debate, most experts seem to agree that the elevated cardiovascular risk seen in these subjects is possibly due to a clustering of risk factors [27]. The correlation between MetS and increased risk CAD has been verified in several epidemiological and clinical studies [28]. Which is the leading cause of death globally. CAD morbidity and mortality are higher in MetS patients; thus, early evaluation of the risk of CAD in MetS patients is important because it may lead to improved adherence of patients or physicians to risk reducing behaviors or treatments and improve clinical outcomes.

The prevalence of SMI in obese subjects versus control group based on GSPECT was 26 per cent and 4 per cent in the present study.

No previous studies have, to our knowledge, focused on the value of G-SPECT using Tc-99 m SestaMIBI for SMI detection in obese Egyptian patients regarding the fact that Egypt is now among the top four countries with the highest incidence of obesity worldwide.

This research used GSPECT as a noninvasive and reproducible method for screening nonovert SMI and to ensure optimum target heart rates; pharmacological stress test [Dipyridamole] was used [29]. Our cases were also positive for MS by meeting $3 / 5$ of the required criteria [WC $>88 \mathrm{~cm}$ in females and $>102 \mathrm{~cm}$ in males, TGs $>150 \mathrm{mg} / \mathrm{dl}$ in males and $\mathrm{HDL}<40 \mathrm{mg} / \mathrm{dl}$ in female]. According to NCEP-ATP III criteria [13]

None of our subjects have been positive for diabetes or hypertension, as such diseases are known as CAD predictors [13]. A large retrospective study was conducted by Vakil et al. [11] on male veterans [n. 1071; >40 percent with MS] for GSPECT detection of SMI and two-dimensional stress echocardiography but lacked controls and female sex in their study.

They found that 21.7 percent met stress imaging criteria for SMI, which was raised to 30 percent in high cases of WC [ $>102 \mathrm{~cm}$ ] comparable to our results [26 per cent]. Low HDL and high TG have traditionally been associated with increased prevalence of SMI [30,31]; Vakil et al. [11] have shown that they have not significantly increased the prevalence of SMI which is consistent with our data as regard the absence of significant association between SMI and TG. While low HDL has shown significant association with SMI in the present study, it was not among the significant predictors using multivariate regression analysis.

Microalbuminuria reflects widespread vascular damage and generalized vascular endothelial dysfunction [32]. The association between microalbuminuria and cardiovascular damage is independent 
of renal function [33]. Besides, it might express the interaction between components of MS [32]. However, in the present study, Multivariate analysis showed that neither WC nor microalbuminuria is significant predictor of SMI in G1. This may be attributed to the small sample size of the study groups and the lack of information regarding the duration of exposure to each individual component of MS which are considered the main limitations of our study.

Finally, previous clinical trials have shown that the presence of SMI predicted an increased risk of future cardiac events $[\mathbf{3 4 , 3 5}$; hence, it remains of paramount importance to screen high risk patients like those with high WC using a non-invasive tool as GSPECT.

\section{Conclusion:}

A substantial association of SMI has been identified among a group of Egyptian obese patients using Tc99 $\mathrm{m}$ Sesta-MIBI GSPECT. Given the fact, we assume that the latter has a position as a screening tool; once the diagnosis is made, the better the result is.

\section{Conflicts of interest:}

The authors declare no conflicts of interest.

\section{References}

1- PEPINE C.J.: Silent myocardial ischemia: Definition, magnitude, and scope of the problem. Cardiol. Clin., 4: 577-81, 1986.

2- DEEDWANIA P.C. and CARBAJAL E.V.: Silent myocardial ischemia. A clinical perspective. Arch. Intern. Med., 151: 2373-82, 1991.

3- KASKI J.C., COSIN SALES J. and ARROYO ESPLIGUERO R.: Silent myocardial ischemia: Clinical relevance and treatment. Expert Opin. Investig Drugs, 14: 423-34, 2005.

4- FORD E.S., GILES W.H. and DIETZ W.H.: Prevalence of the metabolic syndrome among US adults: Findings from the third National Health and Nutrition Examination Survey. JAMA, 287: 356-59, 2002.

5- Centers for Disease Control and Prevention. Obesity Trends in United States. Available at www.cdc.gov/obesity/ data/trends.html/. Accessed January 23, 2012.

6- Expert Panel on Detection, Evaluation, and Treatment of High Blood Cholesterol in Adults. Executive Summary of the Third Report of the National Cholesterol Education Program (NCEP) Expert Panel on Detection, Evaluation, and Treatment of High Blood Cholesterol in Adults (Adult Treatment Panel III). JAMA, 285: 2486-97, 2001.

7- Grundy SM, Cleeman JI, Daniels SR, Donato KA, Eckel RH, Franklin BA, et al. Diagnosis and management of the metabolic syndrome: An American Heart Association/ National Heart, Lung, and Blood Institute Scientific Statement. Circulation, 112: 2735-52, 2005.
8- GENUTH S., ALBERTI K.G., BENNETT P., BUSE J., DEFRONZO R., KAHN R., et al.: Follow-up report on the diagnosis of diabetes mellitus. Diabetes Care, 26: 3160-67, 2003.

9- World Health Organization. Definition, diagnosis and classification of diabetes mellitus and its complications: Report of a WHO Consultation. Part 1: Diagnosis and classification of diabetes mellitus. Geneva, Switzerland: World Health Organization; 1999. Available at http://whqlibdoc.who.int/hq/1999/WHO_NCD_NCS_99. 2.pdf/. Accessed January 23, 2012.

10- ECKEL R.H., GRUNDY S.M. and ZIMMET P.Z.: The metabolic syndrome. Lancet, 365: 1415-28, 2005.

11- VAKIL K.P.1, MALHOTRA S., SAWADA S., CAMPBELL S.R., SAYFO S. and KAMALESH M.: Waist circumference and metabolic syndrome: The risk of silent coronary artery disease in males. Metab. Syndr. Relat. Disord., 10: 225-31, 2002.

12- SNIJDER M.B., VAN DAM R.M., VISSER M. and SEIDELL J.C.: What aspects of body fat are particularly hazardous and how do we measure them? Int. J. Epidemiol., 35: 83-92, 2006.

13- DESPRES J.P., LEMIEUX I., BERGERON J., PIBAROT P., MATHIEU P., LAROSE E., et al.: Abdominal obesity and the metabolic syndrome: Contribution to global cardiometabolic risk. Arterioscler Thromb. Vasc. Biol., 28: 1039-49, 2008.

14- DESPRES J.P.: Targeting abdominal obesity and the metabolic syndrome to manage cardiovascular disease risk. Heart, 95: 1118-24, 2009.

15- BALKAU B., DEANFIELD J.E., DESPRÉS J.P., BASSAND J.P., FOX K.A., SMITH S.C. Jr., et al.: International Day for the Evaluation of Abdominal Obesity (IDEA): A study of waist circumference, cardiovascular disease, and diabetes mellitus in 168,000 primary care patients in 63 countries. Circulation, 116: 1942-51, 2007.

16-KATZMARZYK P.T.1, JANSSEN I., ROSS R., CHURCH T.S. and BLAIR S.N.: The importance of waist circumference in the definition of metabolic syndrome: Prospective analyses of mortality in men. Diabetes Care, 29: 4049, 2006.

17- LAKKA H.M., LAAKSONEN D.E., LAKKA T.A., NISKANEN L.K., KUMPUSALO E., TUOMILEHTO J., et al.: The metabolic syndrome and total and cardiovascular disease mortality in middle-aged men. JAMA, 288: 270916, 2002.

18- de KONING L., MERCHANT A.T., POGUE J. and ANAND S.S.: Waist circumference and waist-to-hip ratio as predictors of cardiovascular events: Meta-regression analysis of prospective studies. Eur. Heart J., 28: 85-56, 2007.

19- WILDMAN R.P.1, McGINN A.P., LIN J., WANG D., MUNTNER P., COHEN H.W., et al.: Cardiovascular disease risk of abdominal obesity vs. metabolic abnormalities. Obesity (Silver Spring), 19: 853-60, 2011.

20- YUSUF S.1, HAWKEN S., OUNPUU S., BAUTISTA L., FRANZOSI M.G., COMMERFORD P., et al.: Obesity and the risk of myocardial infarction in 27,000 participants from 52 countries: A case-control study. Lancet, 366 : 1640-49, 2005. 
21- MOONEY S.J., BAECKER A. and RUNDLE A.G.: Comparison of anthropometric and body composition measures as predictors of components of the metabolic syndrome in a clinical setting. Obes. Res. Clin. Pract, 7: e55-66, 2013.

22- SHAO J., YU L., SHEN X., LI D. and WANG K.: Waistto-height ratio, an optimal predictor for obesity and metabolic syndrome in Chinese adults. J. Nutr. Health Aging, 14: 782-5, 2010.

23- UJJIN P., WIWANITKIT V. and SRIJINDARATANA G.: Evaluation of microalb immunoturbidimetric test for albuminuria screening. Asian Pac. J. Allergy Immunol., 18: 177-80, 2000.

24- HILLEGE H.L., FIDLER V., DIERCKS G.F., van GILST W.H., de ZEEUW D., van VELDHUISEN D.J., et al.: Urinary albumin excretion predicts cardiovascular and non-cardiovascular mortality in general population. Circulation, 106: 1777-82, 2002.

25- American Society of Nuclear Cardiology. Imaging guidelines for nuclear cardiology procedures, Part 2. J. Nucl. Cardiol., 6: G47-G84, 1999.

26- ENAS E.A., MOHAN V., DEEPA M., FAROOQ S., PAZHOOR S. and CHENNIKKARA H.: The metabolic syndrome and dyslipidemia among Asian Indians: A population with high rates of diabetes and premature coronary artery disease. J. Cardiometab. Syndr., 2: 267-75, 2007.

27- YAVUZ B., KABAKCI G., AKSOY H., TULUMEN E., DEVECI O.S., AYTEMIR K., et al.: Determining the relationship between metabolic syndrome score and angiographic severity of coronary artery disease. Int. J. Clin. Pract., 62:717$22,2008$.

28- SAELY C.H., ACZEL S., MARTE T., LANGER P., HOEFLE G. and DREXEL H.: The metabolic syndrome, insulin resistance, and cardiovascular risk in diabetic and nondiabetic patients. J Clin Endocrinol Metab. 2005;90:5698703.
29- AMIN A. and NAWITO O.: Preclinical coronary endothelial dysfunction in Egyptian Behcet's disease patients; Tc-99m SestaMIBI pharmacological Gated-SPECT, is it a useful screening tool? The Egyptian Rheumatologist, 35: 159-6, 2013.

30- TANKÓ L.B.1, BAGGER Y.Z., QIN G., ALEXANDERSEN P., LARSEN P.J. and CHRISTIANSEN C.: Enlarged waist combined with elevated triglycerides is a strong predictor of accelerated atherogenesis and related cardiovascular mortality in postmenopausal women. Circulation, 111: 1883-90, 2005.

31- GAZZARUSO C.1, GARZANITI A., GIORDANETTI S., FALCONE C. and FRATINO P.: Silent coronary artery disease in type 2 diabetes mellitus: The role of Lipoprotein(a), homocysteine and apo(a) polymorphism. Cardiovasc. Diabetol., 22: 1-5, 2002.

32- FRANCIOSI M., PELLEGRINI F., SACCO M., De BERARDIS G., ROSSI M.C., STRIPPOLI G.F., et al.: Identifying patients at risk for microalbuminuria via interaction of the components of the metabolic syndrome: A crosssectional analytic study. Clin. J. Am. Soc. Nephrol., 2: 984-91, 2007.

33- ZAYED H., YOUNIS G., BADER R. and AMIN A.: Prevalence of preclinical renal dysfunction in obese Egyptian patients with primary knee osteoarthritis, preliminary data. The Egyptian Rheumatologist, 35: 239-44, 2013.

34- EKELUND L.G., SUCHINDRAN C.M., McMAHON R.P., HEISS G., LEON A.S., ROMHILT D.W., et al.: Coronary heart disease morbidity and mortality in hypercholesterolemic men predicted from an exercise test: The Lipid Research Clinics Coronary Primary Prevention Trial. J. Am. Coll. Cardiol., 14: 556-63, 1989.

35- SPODICK D.H.: Multiple risk factor intervention trial. Am. J. Cardiol., 56: 1005, 1985.

\section{رابطة نقص تروية عضلة القلب الصامت في مرضى السمنة ويعانون من متلازمة التمثيل الغذائى فئى}

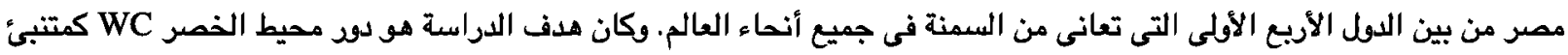

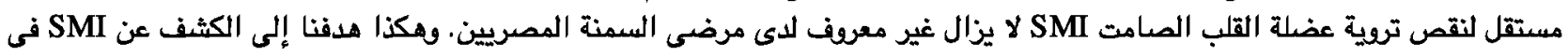

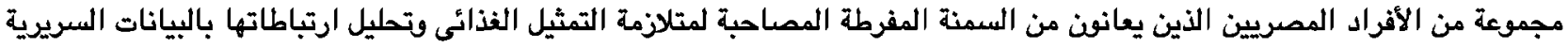

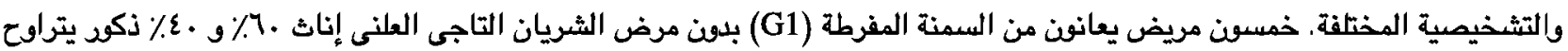

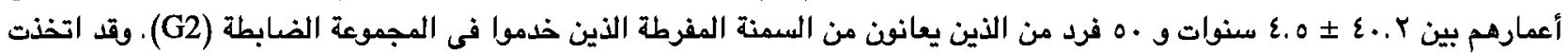

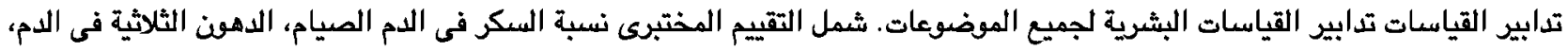

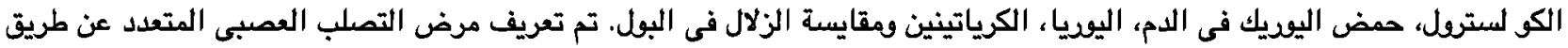

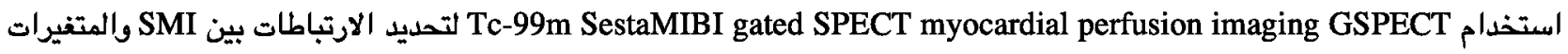

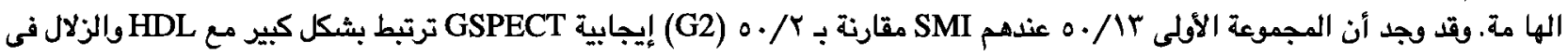

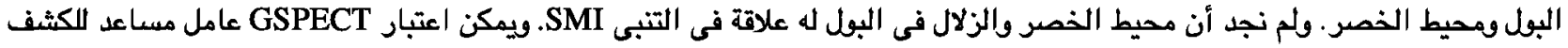

